\title{
Global Localization and Overseas Dissemination of Huang Di Nei Jing English Translation
}

\author{
GAO Yun \\ Shanghai University of Traditional Chinese Medicine, Shanghai, China
}

\begin{abstract}
Aiming to promote overseas acceptance level of the domestic English version of Huang Di Nei Jing Su Wen on the premise of preserving the cultural characteristics of traditional Chinese medicine (TCM), this paper made a comparative analysis of different translations of Chinese character “和” (he) in three English versions of Su Wen, based on the discourse theory of "global localization". The analysis reveals that Li's translation uses the strategy of transliteration plus interpretation to preserve the original Chinese classic's style, thinking, and ideas, but the effect is not satisfactory. Veith's free translation enables overseas readers to understand the content relatively easily, but fails to convey the rich TCM cultural connotation. Unschuld's translation strictly follows the principles of linguistics in order to reflect the original thinking and idea to the utmost extent, and at the same time takes into account the expressions commonly used by the readers of English-speaking countries. That's the reason why his translation enjoys the greatest popularity among professionals and the general public alike overseas. It is also clear from the analysis that different social historical contexts in which Su Wen was translated and each translator's subjectivity determine translation's target audiences, purposes, and ultimately translation strategies. Therefore, in order to speed up the "going out” of TCM culture, domestic translators are suggested to determine target audience and translation purpose in the first place, and study overseas readers' knowledge background, information needs, reading habits, and value orientation before deciding the translation strategies.

Keywords: global localization, TCM culture, Huang Di Nei Jing English translation, overseas readers, translation purposes
\end{abstract}

\section{Introduction}

Traditional Chinese medicine (hereinafter referred to as "TCM") culture has become an important symbol of the internationalization of Chinese culture since its development has been established as a national strategy. TCM classics, reflecting the core of TCM culture, are the treasures of ancient Chinese philosophy and culture. Through the study of their English translation, the core of TCM culture can be understood, recognized, and even promoted worldwide, so that TCM can "go to" the world, which will play an obvious role in promoting the construction and promotion of China's cultural image and soft power. Huang Di Nei Jing (hereinafter referred to as "Nei Jing") is the earliest systematic and complete TCM classics in existence in China. Therefore,

GAO Yun, Master's Degree, Associate Professor, Foreign Language Center, Shanghai University of Traditional Chinese Medicine, Shanghai, China. 
the study of the English translation of Nei Jing is significant in guiding the English translation of TCM classics, as well as their overseas communication and dissemination. Nei Jing is composed of two books, namely Huang Di Nei Jing Su Wen and Huang Di Nei Jing Ling Shu, with 81 copies each. Su Wen, short for Huang Di Nei Jing Su Wen, is "the most widely translated and disseminated classics of TCM abroad so far, and is a must-read monograph for overseas to understanding the TCM culture and theory” (Yin, 2017, p. 35). That's why Library of Chinese Classics, a key national publishing project, has made great effort to organize Chinese renowned translators to translate $\mathrm{Su}$ Wen and promote overseas. However, according to a survey, the overseas acceptance level of this English translation in English and American countries is not high, lower than that of the western versions (Yin, 2017). At present, although there are many studies on the English translation of TCM classics, there are few studies on how to improve the overseas acceptance of TCM classics from the perspective of translatology. Based on the discourse theory of "global localization", this paper aims to compare the English versions of $\mathrm{Su}$ Wen, translated by one Chinese and two western translators respectively, with a view to enlighten domestic translators on how to translate TCM classics into English in a way that is popular with overseas audiences, on the premise of maintaining national cultural characteristics.

\section{“Global Localization” Discourse Theory}

As the main carrier of cross-cultural communication, translation plays an important role in the cultural exchanges of all ethnic groups in the world. Frequent cross-cultural exchanges have promoted the integration of all countries into the trend of globalization. At the same time, this trend has caused people to think about how to maintain the unique characteristics and charm of their own cultures. "Global localization" is a discourse theory of intercultural communication, which deals with the localization process of foreign cultures from a global perspective. After the translation community experienced the initial controversy between "domestication" and "alienation", the theory proposed that the translation process is a two-way cultural communication activity, subverting the one-way communication mode with input limited to one direction from strong discourse to weak discoursein the context of colonization (Liang \& Hu, 2017). Thus, a combination of multiple discourse theories has emerged to counter cultural hegemony and to establish a multicultural world pattern (Wang, 2015). As far as the cultural exchanges between China and the west are concerned, Chinese scholars and translators should learn from the commonly used discourse systems and expressions in the west, and conform to this trend without sacrificing the cultural core of the Chinese nation (Wang, 2011). That is to say, they should "form and disseminate the 'localized' expression of Chinese voice through the way that overseas readers are willing to accept and in the language that overseas readers are easy to understand” (Yan, 2016, p. 18). Then, with the help of the trend of globalization, the cultural differences of language will gradually be overcome, and an equal status in academic and cultural exchanges can be achieved. Therefore, translators need to re-orientate their own national culture, by "taking the initiative to adapt to the ecological environment of translation with their own multicultural consciousness and humanistic character" (Hu \& Guo, 2017, p. 53).

The Chinese character “和” (he) is the essence and core value of Chinese culture and one of the greatest contribution to world civilization (Wang, 2018). “和” (he) can not only promote the harmony between man and nature, but also improve the harmony between man and man, man and society, thus promoting world peace. 
TCM culture embodies the concept of “和” (he) at all levels of its theoretical system. For example, “和” (he) appears 159 times in Nei Jing. Following is a comparative analysis of different English versions of Su Wen, aiming to reveal their differences in expressing Chinese culture and ideas in terms of "localization", as well as in resulting degree of acceptance and attraction in the west.

\section{A Comparative Analysis of Su Wen Translated by Chinese and Westerners}

This paper will make a comparative analysis of three English versions of $\mathrm{Su}$ Wen translated by Chinese and westerners, including the Chinese scholar Li Zhaoguo's version (hereinafter referred to as the "Li's version”), the American scholar Ilza Veith’s version (hereinafter referred to as the "Veith's version”), and the German scholar Paul U. Unschuld's version (hereinafter referred to as the "Unschuld's version"). Although both Li's and Unschuld's translations are full versions, there are only 34 chapters in Veith's version. This study is based on the first 34 chapters of the three versions for comparative analysis.

a. 歧伯对曰: 上古之人, 其知道者, 法于阴阳, 和于术数, 食饮有节, 起居有常, 不妄作劳, 故 能形与神俱, 而尽终其天年, 度百歳乃去。

Li’s version: Qibo answered, “The sages in ancient times who knew the Dao (the tenets for cultivating health) followed [the rules of] Yin and Yang and adjusted Shushu (the ways to cultivate health). [They were] moderate in eating and drinking, regular in working and resting, avoiding any overstrain. That is why [they could maintain a desirable] harmony between the Shen (mind or spirit) and the body, enjoying good health and a long life".

Veith's version: Ch’i Po answered: "In ancient times those people who understood Tao [the way of self cultivation] patterned themselves upon the Yin and the Yang [the two principles in nature] and they lived in harmony with the arts of divination. There was temperance in eating and drinking. Their hours of rising and retiring were regular and not disorderly and wild. By these means the ancients kept their bodies united with their souls, so as to fulfill their allotted span completely, measuring upto a hundred years before they passed away”.

Unschuld's version: Qi Bo responded: “The people of high antiquity, those who knew the Way, they modeled [their behavior] on yin and yang and they complied with the arts and the calculations. [Their] eating and drinking was moderate. [Their] rising and resting had regularity. They did not tax [themselves] with meaningless work. Hence, they were able to keep physical appearance and spirit together, and to exhaust the years [allotted by] heaven. Their life span exceeded one hundred years before they departed".

Analysis: This part summarizes the way of health preservation in TCM culture. The principle of health preservation is to maintain the harmony between heaven and man, mind and body, qi and blood, and its essence is to develop healthy and scientific living habits (Wang, 2018). The three versions are quite different at the level of words, sentences, and layout. Firstly, in translating “和于术数” (he yu shu shu), three translators used verbs of the similar meaning and usage, but they adopted different translation methods for the culture-loaded word “术数” (shushu). Li applied the method of Pinyin plus interpretation, that is, Pinyin “Shushu” is followed by an explanation of "the ways to cultivate health". His original intention is to retain the cultural connotation of the original work, but for the overseas readers, Pinyin "Shushu" may exist lonely becauseit does not relate to the interpretation on the word basis. Veith's translation is "the arts of divination”, which only partly reflects the 
connotation of the original meaning while Unschuld's translation is "arts and calculations" with reference to the annotation. Unschuld'stranslation can express the original meaning of “术” (shu) and “数” (shu) respectively, thus not only retaining the cultural connotation, but also helping the overseas readers understand the term better.

Secondly, the differences lie at sentence level. Take “形与神俱” (xing yu shen ju) as an example. Li’s version adopts literal translation, which is "maintain a desirable harmony between the mind or spirit". Veith's and Unschuld's translations are similar: "keep their bodies united with their souls" and "keep physical appearance and spirit together" respectively. Both of them can resonate with overseas readers by resorting to the linguistic expressions familiar to them, and therefore bringing them closer to the translated text without losing the original texts' cultural connotation. In addition, the three translations display different layouts. Li's and Veith's translations do not preserve the aesthetic features of the original form. Rather, the translators merged the original short sentences into long ones based on the logical relationship between sentences. On the contrary, Unschuld's translation is faithful to the original language's layout by maintaining its mostly short and carefully balanced sentence structures. The beauty of the original form is preserved, thus helping overseas readers enjoy the aesthetics of the original text and appreciate the charm of ancient Chinese.

b. 二八, 肾气盛, 天癸至, 精气溢泻, 阴阳和, 故能有子。

Li's version: At the age of sixteen, as Shenqi (Kidney-Qi) is abundant and Tiangui occurs, he begins to experience spermatic emission. If he has copulated with a woman at this period, he can have a baby.

Veith's version: When he is sixteen years of age the emanations of his testicles become abundant and he begins to secrete semen. He has an abundance of semen which he seeks to dispel; and if at this point the male and the female element unite in harmony, a child can be conceived.

Unschuld's version: With two times eight, the qi of the kidneys abounds; the heaven guiarrives and the essence qi flows away. Yin and yang find harmony. Hence, he can have children.

Analysis: This sentence reveals the philosophy in Chinese traditional culture. It means a man (belongs to Yang) and a woman (belongs to Yin) can have children when they are in harmony together. Therefore, “和” (he) is very important. Only “和” (he) can constantly produce and evolve new things, that is to say, a variety of different things get together in harmonyin order to produce new things (Wang, 2018). This view is reflected in both Li's and Veith's translations of “阴阳和” (yin yang he), with the difference of the former adopting deepened translation while the latter not clear enough in meaning. Unschuld adopted a shallow translation as “Yin and Yang find harmony”, based on the annotation. In addition, in translating culture-loaded words “肾气” (sheng qi) and “天癸” (tian gui), three translators have adopted different translation strategies. Veith’s version features free translation. While her expression is relatively smooth, the cultural connotation of the original text almost disappears. On the other hand, both Li's and Unschuld's versions retain the cultural connotations of TCM terminology, exemplified in their translation of “肾气” as “Shenqi (Kidney-Qi)” and “the Qi of the kidneys" respectively. Their translation methods have their own advantages and disadvantages, but in terms of conformity with the overseas readers'reading habits and fluency of the text, Unschuld's version may be better.

c. 平脾脉来, 和柔相离, 如鸡践地, 曰脾平。

Li's version: The normal Spleen-Pulse beats smoothly and softly as a chicken putting its claw on the ground. This is the normal pulse of the spleen. 
Veith's version: When man is tranquil and healthy the pulse of the spleen flows softly, coming together and falling apart like a chicken treading the earth-and then one can speak of a healthy spleen.

Unschuld's version: The arrival of a normal spleen [movement in the] vessels is [as follows]: harmonious, soft, and distanced, resembling chicken stepping on the earth. That is called "the spleen is normal".

Analysis: In this passage, the Chinese character “和” (he) means “peace and softness”. The three versions are different in translating “和柔相离” (he rou xiang li). Veith’s translation is “softly, coming together and falling apart", which is confusing in meaning. Li translated it as "smoothly and softly" with the meaning of “离” left untranslated. Unschuld's translation is "harmonious, soft, and distanced”, corresponding to each Chinese character in original text. The differences between three versions are also reflected in the translation of the metaphor. Metaphor is a rhetorical device commonly used in Chinese classics and literature. The proper use of rhetoric can more vividly explain TCM and arouse readers' resonance. Li's translation of "putting its claw on the ground" is rather verbose. Veith's and Unschuld's translation are relatively concise and idiomatic. Compared with the verb of "tread" used in Veith's version, Unschuld's translation of "step on" can better express the gentle action process, which is more consistent with “和柔相离” (he rou xiang li), thus helping readers to deepen their understanding of “平脾” (ping pi).

From the above comparative analysis, it can be seen that Li's translation uses the strategy of transliteration plus interpretation "to preserve the original style, thinking and ideas of this great book" (Li, 2009, p. 6), but the effect is not satisfactory. Transliteration is a manifestation of alienation translation. Moderate use of transliteration is an "effective way to maintain the characteristics of TCM and to disseminate TCM culture to the world” (Li, 2011, p. 1572). However, the transliteration method always causes difficulties for readers to understand, and more or less affects the communication of information (Fan \& Tian, 2014). Hence, it should be used sparingly (Wiseman \& Xu, 2004). In addition, some sentences translated literally by $\mathrm{Li}$ are not easy to resonate with overseas readers, thus affecting the appeal of translations. Veith's free translation enables overseas readers to understand the content easily, but cannot convey the rich cultural connotation embodied in the original text. Unschuld's translation strictly follows the principles of linguistics in order to reflect the original thinking and idea to the utmost extent. For one thing, his translation of TCM terms is based on a large number of annotations, so it enjoys a high degree of credibility. For another, in translating sentences, he referred to western expression habits, making language expression more in line with English and American people's language habits and thinking patterns. In addition, the beautiful layout of Unschuld's translation enhances the appeal to overseas readers. For the above reasons, although Unschuld's translation is very professional and more suitable for professional researchers, and what's more, huge number of annotations increase the reading difficulty, it is still welcomed by ordinary overseas readers. As Yin Li said: Unschuld's translation

has maintained the rigor and accuracy of TCM monograph, and also takes into account the expressions commonly used by the readers of English-speaking countries, so it is recognized both in overseas academic circles and readers of Amazon.com. It is the most authoritative translation of Su Wen. (Yin, 2017, p. 39)

\section{Analysis of the Reasons for the Differences}

The differences mentioned above are closely related to the social historical context and the translators' 
subjectivity. The different social historical contexts in which Su Wen was translated, as well as each translator's background knowledge, preference, and interest, determine each version's target audience and purposes, and ultimately the translation strategies to be adopted. The version, finished between 1945 to 1949, by Ms. Weiss, the doctor in the University of Johns Hopkins and the medical historian in the University of California, is the first relatively complete Nei Jing translation by foreigners. During that period, the west has little understanding of TCM although it has been introduced to Europe and the United States. With a view to introducing the main content of Nei Jing to the west, Ms. Weiss adopted the method of medical history and the free translation strategy to meet the understanding level of the average overseas readers (Yang, Li, \& Yu, 2016).

Since 1997, with the establishment of the internationalization strategy of TCM and the development of the publishing industry of TCM books, the overseas influence of TCM has become stronger, and the number of Nei Jing's English versions translated by Chinese and westerners have been increasing. In 2005, Professor Li Zhaoguo, a well-known translator of TCM classics, and Dr. Liu Xiru co-translated Su Wen, and this version was listed as part of Library of Chinese Classics Project. This is the first full English-Chinese Su Wen translation in China. It meets domestic readers' need to study TCM classics, and at the same time is promoted overseas "as a representative of China's highest publishing level and the English translation level of classics" (Yin, 2017, p. 34). In order to reflect the cultural connotation of Su Wen to the utmost, and to maintain its traditional cultural characteristics, Li Zhaoguo advocates the basic principle of "translating the ancient text as what the ancients might read".

Overseas, in 2011, German medical historian Paul U. Unschuld, then director of the Institute of Medical History of Munich University, and Professor Zheng Jinsheng cooperated to complete and publish An Annotated Translation of Huang Di's Inner Classic_Basic Questions. This is the first time that a western language has been used to enable people to read the basic works of Chinese medicine written 2000 years ago. Paul U. Unschuld, with a profound foundation of traditional Chinese medicine, has published the most influential monographs and translations of TCM in the west. By introducing TCM, he aims to help westerners understand Chinese civilization, especially why China has become a global power. Therefore, he "opposes blindly catering to the general reader's understanding level, using western medical terms to translate TCM terms” (Zheng, 2013, p. 8), and strictly "follows the linguistic principles of academic translation of Su Wen" (Unschuld, 2011, p. 9).

\section{Conclusion}

The shift in translation methods and strategies from Veith's free translation to Unschuld's faithful academic translation reflects that western translators have been paying more and more attention to how to convey the characteristics of Chinese national culture in the translation, which greatly promotes the recognition of TCM culture and values by overseas readers. With the rapid increase of China's economic status and comprehensive national strength, China are in more urgent need to boost the international influence of Chinese discourse, and gain wide recognition from other nations and regions in the world than ever before. Therefore, in "localizing” expressions of TCM classics, domestic translators and scholars should commit themselves to make translations understandable and appealing to overseas reader. To achieve this goal, they must in the first place decide who are the target audience and what are the translation purposes. Overseas readers' knowledge background, information needs, reading habits, and value orientation should be studied closely. Only in this 
way can translation strategies be applicable to achieve ideal communication effect. Of course, improving the quality of translation is only one means for TCM classics to "go out". In order to boost the overseas acceptance of TCM classics, it is necessary for state agencies, translators, and publishers to make consistent efforts together.

\section{References}

Fan, Y. N., \& Tian, S. S. (2014). On translation of culture-loaded words in Shanghanlun from the perspective of linguistics of national conditions. China Journal of Traditional Chinese Medicine and Pharmacy, 29(5), 1333-1335.

Hu, W. H., \& Guo, J. R. (2017). A study of Howard Goldblatt's subjectivity from the perspective of eco-translatology. Computer-Assisted Foreign Language Education, (3), 52-57.

Li, Z. G. (2009). Thoughts on English translation of Huang Di Nei Jing. Chinese Science \& Technology Translators Journal, (4), 3-7.

Li, Y. A. (2011). The embodiment of "orientalization" in the standardization of English translation of two sets of TCM terms. Chinese Journal of Integrative Medicine, 31(11), 1570-1572.

Liang, M. L., \& Hu, W. H. (2017). “Global localization” in English translation of foreign media’s "Hong Huang Zhi Li”. Shanghai Journal of Translators, (6), 38-41.

Unschuld, P. U. (2011). Huang Di Nei Jing Su Wen: An annotated translation of Huang Di’s inner classic-Basic questions. Berkeley: University of California Press.

Wang, N. (2011). Comparative literature: Theoretical thinking and literary explanation. Shanghai: Fudan University Press.

Wang, P. (2015). The implicit impact of global culture and translation. In N. Wang (Ed.), Frontier of literary theory series 13 (pp. 196-214). Beijing: Tsinghua University Press.

Wang, Q. Q. (2018). Harmony: “和” thought of traditional Chinese medicine and Chinese traditional culture. In H. R. Zhu (Ed.), Ten talks by famous Chinese medicine experts (pp. 79-90). Shanghai: Shanghai Jiaotong University Press.

Wiseman, N., \& Xu, Q. W. (2004). English translation of TCM nouns: A translation model based on the principle of systematization. Chinese Terminology, 6(4), 30-34.

Yan, W. B. (2016). "Self-constructing” and "other-constructing” of China’s international image. International Communications, (6), 17-18.

Yang, L., Li, H. D., \& Yu, H. B. (2016). A review on publication of Huang Di Nei Jing's English versions. Research on the History of Publishing in China, (1), 134-144.

Yin, L. (2017). Investigation and enlightenment on the overseas acceptance of domestic English versions of traditional Chinese medicine books: A case study of the English version of Huang Di Nei Jing of library of Chinese classics. Journal of Foreign Languages, 40(5), 33-42.

Zheng, J. S. (2013). Prof. Unschuld's path of researching the history of medicine in China. The Chinese Journal for the History of Science and Technology, 34(1), 1-17. 